Alberto M. Binder1

\title{
Entre la democracia y la exclusión: la lucha por la legalidad en una sociedad desigual
}

\section{Las buenas razones para no confiar en la ley y en los sistemas judiciales}

No es fácil creer en la ley en América Latina. No es fácil hacerlo cuando ella convive tranquila $-y$ a veces sin inmutarse siquiera - con situaciones de desigualdad, exclusión y pobreza que poco tienen que ver con la igualdad, la libertad y la dignidad de los seres humanos y menos aún con la pretensión de generalidad de la ley. Más difícil todavía es argumentar a favor de ella. Si se trata de una persona joven, quizás de una o varias generaciones enteras, que no ha tenido experiencia directa con las dictaduras militares y los momentos de gran opresión, la ley y el derecho pueden llegar a ser palabras sin sentido, meras fórmulas vacías que justifican el trabajo del abogado, pero que a nadie conmueven. De un modo u otro, la lucha por el cumplimiento de la ley no entusiasma a grandes sectores sociales y en especial a las nuevas generaciones. Para otros tantos, es una palabra bonita o "seria", pero que carece de fuerza política. En el mejor de los casos, un ideal ético o una buena costumbre que habla bien de quien cree en ellas pero que a nadie perturba o moviliza con profundidad.

La perdida de la fuerza política de la ley o, lo que es lo mismo, la perdida de su fuerza normativa, es una de las grandes calamidades de nuestra región, una verdadera peste, que todos conocemos con el nombre de impunidad estructural. Esta impunidad, a la que ya nos hemos acostumbrado, es la contracara de la República, porque encubre al poder concentrado y su distribución de privilegios; es la contracara de la democracia, porque torna inútil los pactos políticos y la actividad parlamentaria y es la burla más hiriente del Estado de derecho, porque lo convierte en una fachada o una máscara que oculta el abuso de poder. Se podrá decir que esta descripción es exagerada o puramente literaria y que nada es blanco o negro en los procesos sociales o políticos. Por supuesto que es así. La realidad es variopinta, pero de lo que se trata es de abandonar el tono neutro 
y tímido y falsamente académico cuando hablamos de los problemas del cumplimiento de la ley y recuperar el "lenguaje fuerte o recio" que usaban quienes realmente creían que la ley podría ser un instrumento idóneo para la construcción de una sociedad republicana, democrática, regida por la razonabilidad de la actuación pública y al servicio de la igualdad y la libertad de todos los hombres y no sólo de algunos. Verdades e ideales de a puño, que nos hemos acostumbrado a convertir en frases de cortesía o notas al pie de página o clases aburridas frente a alumnos más aburridos todavía.

Es común atribuir este problema a un defecto de los ciudadanos. La falta de educación cívica, las tendencias autoritarias o populistas que nacen de la propia cultura, la comodidad de la sumisión, el sentido mesiánico que produce líderes carismáticos, el egoísmo, la desarticulación social, el analfabetismo y otros males de la gente son los que causan este descreimiento ante la ley. Por el contrario, las personas cultas, los líderes políticos, los intelectuales comprometidos, los sectores empresarios, los funcionarios del Estado y otros grupos sociales con "conciencia cívica", son quienes proclaman el cumplimiento de la ley. En los últimos tiempos esto se ha intensificado con los reclamos de seguridad jurídica que provienen de muchos de esos sectores, como una condición ineludible del crecimiento y el desarrollo social. Nada más alejado de la realidad. En un sentido o en otro. Justamente son los sectores dirigentes de nuestras sociedades quienes proclaman la inutilidad de la ley (que muchos de ellos provocan o agravan) o se han acostumbrado a convivir con instituciones que no se aplican, se aplican malamente o de un modo totalmente distorsionado.

Ello podría haber generado una sociedad con pocas leyes y con pocos discursos "institucionalistas". Pero no es así. Al contrario, vivimos en una sociedad donde el incumplimiento sistemático de la ley se oculta tras una cortina de nomatividad profusa. Muchas leyes que nadie conoce y nadie aplica. Un orden jurídico "gaseoso", una producción normativa descontrolada y muchas veces irresponsable y una técnica legislativa confusa y favorecedora de la litigiosidad. Tras esta cortina de humo, producida por la "inflación legislativa", ha nacido, crece y se reproduce la sociedad de privilegios, cuya peor versión es la exclusión social de grandes sectores de la población y cuya mayor insensatez es la exclusión, a veces masiva, de las nuevas generaciones. Como piensa el Niño Remigio, el personaje de Manuel Scorza, "el peor de los castigos es la exclusión. El animal que ha inventado la risa necesita un eco"2.

El ciudadano común que no cree en la ley y desconfía de los sistemas judiciales tiene muy buenas razones para hacerlo. Solo le basta mirar a su alrededor. Allí descubrirá que los derechos más elementales no se cumplen. Por ejemplo, que las Constituciones obligan, bien o mal, a una salario digno y luego las condiciones de trabajo son lindantes con la esclavitud. $O$ que la niñez está protegida por códigos enteros y luego pocos pueden ir a la escuela y muchos deben trabajar o 
conseguir su sustento en las calles. $O$ que se proclama el derecho a la salud y luego no hay un hospital donde ir. Se proclama la igualdad de la mujer y la vida cotidiana la desmiente cotidianamente. Las leyes obligan a pagar impuestos que no se pagan. Obliga a imponer castigos que no se imponen o no se cumplen. Todo esto en un nivel muy básico y muy evidente. Se dirá - y es un tema central de discusión política en América Latina- que nuestras leyes no tienen sentido de realidad o que existe una discordancia fundamental entre la visión del hombre sobre la legislación y la concepción de la actividad económica. Se dirá también que, en realidad, las condiciones de producción de riqueza hoy permiten cumplir con lo que las leyes proclaman, pero el grado de desarrollo ético de la sociedad es muy distinto a su capacidad tecnológica. En fin, se puede discutir este problema desde muy variados ángulos, pero todos ellos parten de una evidencia, casi física, de que muchas leyes elementales y fundamentales no se cumplen, se hace poco para hacerlas cumplir y ya estamos acostumbrados a que esto sea así. Este ciudadano que observa sin mucho esfuerzo esta realidad, si agudiza su mirada, podrá observar que, además, los abogados justifican estos incumplimientos e, incluso, llegan a construir teorías prestigiosas para demostrar que es correcto que no se cumplan o explican el derecho sin advertir el carácter estructural de su ineficacia. Además, podrá ver a decenas de miles de estudiantes de abogacía que pasan años en las escuelas de leyes sin inmutarse por este incumplimiento endémico y masivo de la ley. A veces ni siquiera toman nota de ello y se sorprenden cuando deben asesorar sus primeros casos profesionales.

Este fenómeno puede llevar a situaciones límite. Como señala Carlos Nino, "la existencia en la sociedad argentina de una pronunciada tendencia general a la ilegalidad y a la anomia resulta bastante fácil de percibir. Es suficiente con tener presente la forma en que se violaron masivamente los derechos humanos en la década de los setenta a través de un terrorismo de Estado que desconoció la propia legalidad impuesta por el régimen militar.". Palabras más o palabras menos esta descripción se puede aplicar a casi todos los países de América Latina. No sólo hemos tenido una historia de dictaduras y golpes de Estado, de quiebres institucionales variados y de violencia, sino de dictaduras que no respetaban sus propias reglas, de regímenes fraudulentos que terminaban por hacerse trampa a sí mismos, de ordenes jurídicos construidos a fuerza de decretos del Poder Ejecutivo o leyes de privilegio, que luego tampoco se cumplían, en un juego de espejos al infinito, que marca la profundidad y la gravedad del incumplimiento de la ley en nuestra región.

La contracara de esta realidad anómica es la debilidad de nuestros sistemas judiciales. Debilidad de la ley y debilidad de los jueces son dos miradas sobre el mismo fenómeno y es muy difícil saber cual comenzó primero. La debilidad del Poder Judicial en América Latina es histórica y responde a su proceso de formación institucional. La “justicia del rey”, trasladada por españoles, portugueses y franceses, ratificada a lo largo de las centurias, funcional a los intereses colonia- 
les y a la concentración del poder, nunca fue pensada para convertirse en una justicia republicana, que hiciera cumplir la ley. Así lo dice Francisco Tomás y Valiente: “El rey es el principio y referente de toda actividad de poder y quien tenga poder (ya sea de justicia o de gobierno, conceptos entonces no diferenciados) los tiene porque del rey le viene (...) lo que el rey ha delegado es revocable en cualquier momento, ya se trate de la enajenación o venta por precio de un oficio -el rey siempre podía recuperarlo- ya se trate de una delegación concreta en un órgano permanente. Es decir, el rey retiene en sí mismo la justicia y con ello la posibilidad de abocar para sí cualquier proceso, cualquier asunto de justicia aunque esté atribuido a otros órganos de la administración'4.

A lo largo de nuestra historia institucional esta dependencia originaria fue acentuándose. Los caudillos y presidentes manipularon a los jueces y los jueces se dejaron manipular. Los Tribunales Superiores avalaron las dictaduras militares y éstas sostenían a tribunales que les daban cierta legitimidád superficial. Ocurrieron matanzas memorables, golpes de Estado cruentos, rebeliones, alzamientos, opresiones, se firmaron contratos que establecieron privilegios irritantes para empresas extranjeras, se mantuvo la servidumbre hasta bien entrado el siglo XX, se expropió ilegalmente, se usurparon tierras, se mató, ejecutó o desaparecieron los ciudadanos y el Poder Judicial siempre se mantuvo al margen, entretenido en el lento tramitar de expedientes polvorientos, en la repetición mágica de fórmulas vacías, en una crueldad convertida en rutina, que mantuvo siempre a los pobres en la cárcel. Hubo jueces que se rebelaron frente a esta situación, pero fueron echados, encarcelados, asesinados o repudiados. El propio sistema judicial se preocupó de marginar a quienes no aceptaban esta situación y de volver sumisos a quienes pretendían renovar la cultura judicial. Hoy, ya a finales del siglo, nos encontramos con una administración de justicia tan débil como entonces y todavía poco dispuesta a construir su verdadera fortaleza.

Se impone, pues, la conclusión de este primer apartado: los ciudadanos tienen muy buenas razones para desconfiar de la ley y de los jueces. No se trata de un defecto de la educación cívica. Al contrario, esa desconfianza se nutre de una decisión racional, a la cual llegaría sin dificultades cualquier analista experto: en las actuales condiciones institucionales de América Latina quien apueste a la ley y al funcionamiento de los sistemas judiciales asume riesgos que no son razonables. Es altamente probable que ellas no funcionen o lo hagan de un modo tardío o las decisiones finalmente sean arbitrarias. Si se trata de sectores sociales débiles, con escaso margen para la perdida y la recuperación, esa decisión puede ser más irrazonable todavía. Se ha invertido, entonces, la fórmula básica del Estado de derecho, que ahora dice: cuanto más débil es una persona o un sector social, más irrazonable es que confie en la ley y los tribunales, para la consecución de sus intereses o la satisfacción de sus necesidades. 


\section{La pérdida de fuerza normativa de la ley Ideales éticos y desesperanza}

Sin embargo, todavía resuena en América Latina el eco de un viejo entusiasmo por la ley y los tribunales. Al inicio del siglo XIX, la prosa jurídica, tanto en el viejo como en el nuevo continente, abandona el tono doctoral y rebuscado al que la habían llevado los juristas anteriores y adquiere un lustre panfletario y combativo. Los discursos normativos utilizan un lenguaje que tiene fuerza y golpea a la realidad del Antiguo Régimen de la Monarquía absoluta o al gradualismo del despotismo ilustrado.

El movimiento de la Ilustración cree en la ley, porque ella es expresión de la razón y de la verdad. Norma inmutable, acompasa el orden natural y el humano en una ammonía universal. "Fue un lenguaje del despotismo y de la tiranía - nos dice Filangieri- decir que la voluntad del legislador es la única regla de la legislación: y es un error nacido de la ignorancia creer que en medio de las revoluciones que mudan continuamente la naturaleza de los negocios, y cambian el semblante de la sociedad, la Ciencia Legislativa no pueda tener algunos principios fijos, determinados e inmutables"s.

Pero la búsqueda de afincar la ley en principios inmutables no es afectación intelectual ni mero postulado de escuela. Se trata de un debate cultural, propio del momento en que los viejos ideales éticos del humanismo se convierten en principios políticos. Afincar la ley en la naturaleza era demostrar la locura de los regímenes monárquicos, que pretendían tener su sustento en la voluntad divina. Era, además, un modo de construir un nuevo poder para la ley, entendida como manifestación democrática de la voluntad general y convertirla, a su vez, en el instrumento de una nueva manera de ejercer el poder mismo. Era el abandono del legalismo arbitrario de la monarquía absoluta o el legalismo desigual de la sociedad feudal. Se trataba de la construcción de un nuevo orden normativo, que necesitaba una nueva cultura. La fuerza de estas ideas se vuelve transparente en Rousseau: "Cuándo se ve cómo en los pueblos más dichosos del mundo un montón de campesinos arreglaba bajo una encina los negocios del Estado, conduciéndose siempre sabiamente, ipuede uno dejar de despreciar los refinamientos de otras naciones que se vuelven ilustres y miserables con tanto arte y tanto misterio? Un Estado así necesita pocas leyes, y cuando se hace necesaria la promulgación de otras nuevas, tal necesidad es universalmente reconocida. El primero que las propone no hace más que interpretar el sentimiento de los demás, y sin intrigas ni elocuencias, pasa a ser ley lo que de antemano cada cual había resuelto hacer una vez seguro de que los demás harán como él"’.

La renovada esperanza en la ley no nace en el vacío. Al contrario, nace como una crítica a los modos de gobiemo anteriores, repletos de normas y sutilezas y de un lenguaje oscuro. "Su estilo debe ser conciso. Las Leyes de las doce tablas son un modelo de precisión: los niños se las aprendían de memoria. Las Novelas 
de Justiniano son tan difusas que fue preciso abreviarlas. El estilo de las leyes debe ser sencillo; la expresión directa se entiende mejor que la expresión redundante. No hay majestad en las leyes del bajo imperio, pues los príncipes hablan en ellas como retóricos. Cuando el estilo de las leyes es ampuloso, se consideran como obra de ostentación. (...) Las leyes no deben ser sutiles, pues están hechos para gentes de entendimiento medio. No son un arte de lógica, sino el argumento sencillo de un padre de familia" (Montesquieu) ${ }^{7}$.

Este entusiasmo por la ley, bajo su nueva virtud, llegó a América al igual que los ideales del humanismo y las ideas de la Ilustración. Se convierte en piedra angular del pensamiento de la revolución norteamericana y palabra encendida en las guerras de independencia del sur. No en doctrinas de abogados, sino en principios de acción política. "Que un plantador sin capacitación legal (George Mason) haya redactado un documento como la Declaración de Derechos de Virginia debe permanecer como fuente de perplejidad (...) Mason era un plantador poco educado en colegios. Sin embargo, conocía a Locke, a Montesquieu y a Sydney, el trío que proporcionó apuntalamiento teórico a la Revolución norteamericana".

Algo similar ocurre en las guerras de la independencia latinoamericanas, donde los guerreros ilustrados son también quienes proclaman la cultura de la legalidad, en una paradoja que nos ha acompañado desde entonces. En este, como en tantos otros temas, Bolívar es paradigma y anticipación. Pára Bolívar, la vieja legislación española era el "suplicio más refinado que la cólera del cielo ha permitido descargar sobre este desdichado imperio"s". Y frente a ella propiciaba un respeto sagrado por las leyes, sin el cual la sociedad se convierte en un "conflicto singular de hombre a hombre, de cuerpo a cuerpo"'". "La verdadera Constitución liberal está en los Códigos Civiles y Criminales; y la más terrible tiranía la ejercen los Tribunales por el tremendo instrumento de las leyes. De ordinario el Ejecutivo no es más que el depositario de la cosa pública; pero los Tribunales son los árbitros de las cosas propias, de las cosas de los individuos"'1. "Que las leyes se cumplan religiosamente y se tengan por inexorables como el Destino"'2.

Muchos otros líderes de la independencia proclamaban las mismas ideas; Artigas sostiene que "es muy veleidosa la probidad de los hombres, sólo el freno de una Constitución puede afirmarla". O Juan Germán Roscio: "El poder legislativo (...) es la más ventajosa facultad que el hombre recibió de su autor. Es el producto de su razón ilustrada (...) sanción recta del entendimiento que ordena lo bueno y prohibe lo malo. Ved aquí la fuerza moral, a cuyo dulce y suave imperio, sin violencia ni repugnancia, vive sometido el hombre de bien". O José de San Martín: "Cuando se hallen restablecidos los derechos de la especie humana perdidos por tantas edades en el Perú, yo me felicitaré de poderme unir a las instituciones que los consagren, habré satisfecho el mejor voto de mi corazón y quedará concluida la obra más bella de mi vida"13. 
¿Qué quedó de ese entusiasmo? ¿Qué pasó con la legalidad? ¿En qué quedó la esperanza de sociedades regidas por el dulce y suave imperio de la ley?

Tanto en Europa como en América, el tránsito de los ideales éticos del humanismo a la dimensión política de la nueva cultura de la legalidad inauguró una época de conflictos y desesperanzas, que llevó a decir a Simón Bolívar —el más fuerte de los americanos - "no tengo fuerza para domar un mundo". O llevó a Robespierre —l más consecuente de los legalistas - a matar y morir en el Terror. Los ideales éticos del humanismo renacentista nutrieron la esperanza en un mundo liberado. La ley de los ilustrados entusiasmó como instrumento político de emancipación. Hoy hemos perdido la esperanza de los ideales y pocos creen que la ley pueda ser un instrumento político de liberación.

El pensamiento jurídico dedicó buena parte de los últimos dos siglos a cimentar estos sentimientos. Poco a poco fue desmontando la fuerza normativa del derecho, a la vez que la desvinculaba de sus ideales éticos. El pensamiento jurídico ha Estado al servicio de la debilidad de la ley y, por extensión, de la debilidad de los jueces. Una interpretación rígida y despolitizada (exégesis) restauró el lenguaje docto y rebuscado de la escolástica tardía y sus clasificaciones exasperantes. Nuevos conceptos jurídicos se amoldaron rápidamente a este derecho sin fuerza normativa. Se lo separó de un modo tajante de la costumbre y la cultura, se lo proclamó único, indivisible, completo, armónico y se lo alejó de la política. Se lo identificó de un modo absoluto con todo acto de autoridad y se le hizo perder toda capacidad de interpelación al poder y a la sociedad. Se lo volvió abstracto e inexigible, alejándolo de los débiles y necesitados. Se lo usó como un lenguaje del poder, como una máscara de legitimación, como un objeto de culto en las academias burocráticas. Se lo dividió en infinitos segmentos, se lo convirtió en un laberinto, sólo apto para espęcialistas y profesionales. Se lo apropiaron los jueces técnicos, los profesores, los legisladores profesionales (asesores) y toda una clase burocrática que lo utilizó como su rutina y sustento.

Por otra parte, los jueces de América Latina se encargaron de volver progresivamente inaplicable toda conquista social. El derecho dejó de ser un instrumento de transformación, ni siquiera intento serlo. Y así, poco a poco, se restableció la sociedad de privilegios, ahora recubierta por una trama compleja de normas, que cumplen la misma función que antes cumplían las supersticiones y doctrinas religiosas en la legitimación del poder absoluto.

Pero sería insensatez y petulancia sostener que todo fue un juego de ilusiones de los patriotas y filósofos del ochocientos. No lo fue. Lo que ocurrió es que la lucha por la legalidad fue derrotada, tan derrotada en las comunas de Francia como en las montañas y planicies de nuestra América Latina. El pensamiento jurídico se ha construido sobre la base de una derrota descomunal y no nos ha ayudado siquiera a comprenderla. Los ideales éticos quedaron en pie, pero entreverados con los esqueletos sin fuerza de las normas derrotadas. 
Una crítica profunda al pensamiento jurídico por su complicidad y ocultación de la derrota de eficacia de la ley. Una reflexión renovada sobre los ideales éticos del humanismo y una crítica radical al sistema judicial inquisitivo como justicia del poder concentrado y de la sociedad de privilegios, son los tres pilares de una reconstrucción de la esperanza en los derechos del hombre y del entusiasmo por la ley, que pueda ser asumida por todos los ciudadanos, en especial por quienes más necesitan de ellas.

Pero si existen muy buenas razones para no confiar en la ley ni en los tribunales, ¿de dónde sacaremos ese entusiasmo y para qué nos sirve esa esperanza?

\section{Razones para no ser violentos \\ La profundización de la democracia}

Una nueva reflexión sobre la ley en América Latina es inescindible de una reflexión sobre la democracia y su futuro. Aun más, el futuro de una y otra se hallan tan indisolublemente unidos, como el de la democracia y la república. Estado de derecho (imperio de la ley), República (fragmentación y control del poder) y democracia (igualdad y soberanía popular) constituyen un único problema político del cual depende el desarrollo institucional de nuestros países y buena parte de nuestro futuro.

Pero estas tres dimensiones no son abstractas; al contrario, se hallan tensionadas por otras realidades sociales y, en especial, por las condiciones de vida concreta de los ciudadanos. En América Latina no terminamos de asumir que cualquiera de los problemas políticos que plantean esas tres realidades básicas, se manifiesta siempre en el contexto de una sociedad desigual. Tenemos que construir una República, una democracia y un Estado de derecho en una sociedad desigual y en la que esa desigualdad no es sólo pura diferencia, sino que significa que sectores mayoritarios, o por lo menos millones de personas, viven muy por debajo de las condiciones elementales de una vida digna. Pensar estas tres realidades en el marco de una sociedad desigual de esas características significa que ellas deben estar fuertemente orientadas a revertir esa desigualdad. Podrán tener otras tareas, pero es impensable en América Latina una democracia cuyo principal problema no sea revertir las condiciones de desigualdad. Eso no es un tema dentro del sistema democrático, es un tema del sistema democrático mismo. Lo mismo sucede con la República y con el Estado de derecho.

Hay un punto en el que la democracia ya no es un puro procedimiento, sino que lleva en sí misma un elemento de crítica social, sin el cual deja de ser democracia. Este es el problema de las democracias formales o sustanciales. En una sociedad desigual como la de nuestros países, es decir, con contrastes muy altos y con sectores por debajo del nivel de subsistencia, la idea de la democracia misma está asociada a una fuerte política de reversión de esas condiciones de 
desigualdad. Es decir, ella debe construir de un modo prioritario su base social igualitaria, que no quiere decir lo mismo que un estado de justicia social, sino el mínimo imprescindible para que los principios del sistema democrático tengan virtualidad y no sean una ficción. En las sociedades latinoamericanas estamos lejos de ese mínimo y por eso la democracia tiene una tarea preasignada por la realidad social, una política pública que es inescindible de ella misma.

Pero ello no quiere decir que esa construcción deba estar por fuera del mismo proceso democrático. Al contrario, este carácter circular del proceso democrático es su mayor riqueza. Se pensó en otros momentos en nuestros países que la construcción de esa base social para la democracia debía ser realizada por otros métodos o con otras urgencias, ya que la democracia había sido antes que nada un sistema político de fachada. Gobiemos altamente centralizados pero con conciencia social, movimientos amados o francas dictaduras eran herramientas mucho más idóneas para la construcción de esa base social que permitiría el ejercicio de la plena democracia. Estos intentos no han dado los resultados esperados ya sea por sus propios defectos de concepción o por las presiones externas que no dejaron desartollarlos. De un modo u otro, participaron de estallidos de violencia que dejaron ya huellas profundas en la memoria latinoamericana.

América Latina se enfrenta a un desafío de gran magnitud. Por una parte, la recuperación de los sistemas democráticos, así como la vitalidad de las ideas que los sustentan, abren una renovada esperanza para el desarrollo institucional de la región y nuevas posibilidades para la estabilidad, la paz y la inserción en el escenario mundial. Por otra parte, el aumento de la pobreza, la consolidación de grandes brechas de desigualdad en la distribución de la riqueza y las oportunidades sociales, la postergación de demandas sociales elementales y la falta de empleo, siembran una vez más dudas en muchos sectores sociales sobre la efectiva capacidad de la democracia para enfrentar estos problemas dentro del horizonte vital de esas generaciones. Esta tensión entre los principios básicos de la democracia y las condiciones de vida de millones de personas, apunta a uno de los elementos centrales de la idea de gobernabilidad democrática, que no puede ser comprendida sólo en términos de estabilidad o eficacia en la gestión estatal, sino también por su capacidad para poner a disposición de todos los sectores sociales los instrumentos democráticos para que sean estos mismos sectores quienes procuren la satisfacción de sus demandas e intereses. El uso de los instrumentos democráticos por la mayor cantidad posible de sectores sociales, en especial por aquéllos que tienen demandas elementales insatisfechas, se convierte en una de las variables cruciales a la hora de evaluar la gobernabilidad del sistema democrático y, a la vez, es una de las variables de esa gobernabilidad que influyen de modo más directo sobre la legitimidad del sistema.

La histórica injusticia de las sociedades latinoamericanas nos lleva a ser impacientes. No siempre debemos hacer una lectura negativa de esa impaciencia 
porque ella es el resultado de la sensibilidad, de la solidaridad y del amor a los semejantes. Es sano para una sociedad que cada generación mantenga la impaciencia por construir una sociedad más justa. Mucho más sano aún es que las generaciones más jóvenes mantengan esa impaciencia. Una política que no se nutre de esa impaciencia se convierte en mera administración de lo que existe, le falta la capacidad de transformar la realidad. La política no es el arte de lo posible; es el arte de imaginar sociedades distintas y volverlas posibles. Es un oficio de impacientes.

La profundización de la democracia nos da la oportunidad de no ser violentos. Nos da la oportunidad, también, de ser impacientes. De ser impacientes, sin ser violentos. Pero para ello la democracia debe ser un sistema que interpele a la sociedad, que tenga capacidad de construir una base social democrática, de un modo democrático. Modo democrático y base democrática se implican mutuamente y ambas interpelan a las otras políticas, en especial a la política económica, cuya preocupación central debe ser construir las condiciones de vida digna de todos los habitantes del país, sin exclusiones, y a la política educativa, que debe poner al alcance de todos los habitantes los instrumentos necesarios para el desarrollo personal.

Para profundizar la democracia es necesario desarrollar todos los instrumentos de democracia participativa. La reducción de la representatividad es también una tarea propia del sistema democrático. La democracia directa no es una utopía o un modelo válido para pequeñas comunidades, sino una tarea permanente de reducción de la representatividad, sin pérdida de la eficiencia necesaria para gobernar. Es una construcción permanente de una base más amplia para la democracia. En este sentido, la idea de profundización de la democracia tiene dos dimensiones paralelas: el aumento de los instrumentos de participación y la generación de condiciones sociales igualitarias. Estas dos dimensiones se complementan porque lo que define al propio sistema democrático es que la construcción de esa sociedad igualitaria se realiza a través de la profundización de esos instrumentos y la profundización de esos instrumentos sólo es posible si están al servicio de la construcción de esa base igualitaria. Como ya dijimos, este carácter circular es una virtud de la democracia.

Pero para que la profundización de la democracia sea un proyecto político que entusiasme no debe ser una propuesta mediocre. Para que la democracia entusiasme y forme a la nuevas generaciones debe ser un proyecto fuerte, si se quiere radical, que interpele, moleste y genere riesgos. Se ha vuelto muy cómodo ser demócrata en América Latina y eso es un signo de superficialización de la democracia. Algo similar sucede con la legalidad. Es muy fácil hablar del cumplimiento de la ley porque ya es un discurso rutinario, una postura fácilmente aceptada y que no conmueve. Para que la lucha por el derecho tenga sentido en América Latina y entusiasme a los más jóvenes es necesario que vuelva a 
tener capacidad de interpelar a la sociedad. Debe ser una proclama molesta. Una crítica incómoda, una postura riesgosa. De eso se trata en definitiva, de radicalizar la lucha por la legalidad.

\section{La lucha por el derecho: un enfoque radical}

Rudolf von Ihering, uno de los más grandes e influyentes juristas alemanes del siglo XIX, escribió una pequeña obra que pronto tuvo un gran éxito, La lucha por el derecho ${ }^{14}$. Una breve antología de párrafos de esa obra nos puede servir de introducción, no sólo por su contenido, sino por el estilo y su fuerza que muchos "juristas" de esta época considerarían impropia de un libro sobre el derecho. Nos dice, por ejemplo, "al que no siente que cuando su derecho es despreciado en forma ofensiva o pisoteado, no sólo está en juego el objeto del mismo, sino su propia persona; al que en tan situación, no siente el impulso a sostener su persona y su buen derecho, no vale la pena ayudarle y yo no tengo ningún interés en convertirlo.(...). Para él no tengo otra palabra que la de Kant, "el que se hace gusano no puede quejarse después de que sea pisoteado", o "No dejéis que vuestro derecho sea impunemente pisoteado por otros"15. Ni Ihering ni Kant, utilizan el lenguaje "neutro" de nuestros profesores de leyes. Vale también esta otra cita: "La condescendencia y la conciliación, la moderación y el ánimo pacífico, la avenencia y la renuncia a la imposición del derecho encuentran también en mi teoría el puesto que les corresponde; contra lo que se declara es simplemente contra la tolerancia indigna de la injusticia por cobardia, comodidad, indolencia"16. Podemos continuar: "Todo derecho en el mundo ha sido logrado por la lucha, todo precepto jurídico importante ha tenido primero que ser arrancado a aquéllos que le resisten y todo derecho, tanto el derecho de un pueblo como el de un individuo, presupone la disposición constante para su afirmación"17. "Sin lucha no hay derecho, como sin trabajo no hay propiedad. La norma "comerás el pan con el sudor de tu frente", está con la misma verdad frente a la otra: "en la lucha hallarás tu derecho". Desde el momento en que el derecho abandona su disposición combativa, se sacrifica a sí mismo. También para el derecho vale la sentencia del poeta: Esta es la conclusión de la sabiduría. Sólo merece la libertad y la vida, el que tiene que conquistarlas diariamente" ${ }^{18}$.

No nos interesa aquí adherir completamente a la concepción de lhering o discutir si la defensa del derecho es a la vez una obligación del ciudadano, como él sostiene. Lo cierto es que la concepción de Ihering es una concepción de lucha radical por la legalidad y esto nos da pie para recuperar una tradición abandonada por un pensamiento jurídico curialésco, anodino y petulante, que no entusiasma ni siquiera a los abogados y que ha contribuido de un modo eminente a la pérdida de fuerza de las nomas y a desactivar la lucha por el derecho en nuestras democracias. 
No sólo Ihering sostiene una lucha radical por el cumplimiento de la ley. Otro jurista clásico, Francesco Carrara, muestra el mismo entusiasmo y la misma convicción:

Se nos ha garantizado la inviolabilidad de la persona, la inviolabilidad del domicilio, la inviolabilidad de la propiedad privada. Pero estas palabras (...) ¿de que' le sirven a un pueblo que no es capaz de hacerlas observar? Si a pesar de la inviolabilidad que se ha proclamado, cuando los órganos subalternos del poder violan domicilios o personas, los ciudadanos no saben sino someterse con servil paciencia, o con modos violentos hacerse indebidamente justicia, ni tampoco saben reclamar sus derechos en forma legítima con firmeza y con calma, ante los abusos; si a pesar de la inviolabilidad de los bienes que se ha proclamado, las propiedades privadas son conculcadas en un afán por seguir nuevas teorías económicas, o los patrimonios se llevan al desastre a causa de las maquinaciones de procedimientos insensatos, $i$ la culpa de todo esto se encuentra en las instituciones políticas?.(..) Tenemos la libertad de petición. Pero si al pedir no nos unimos y no nos ponemos de acuerdo (...) Se nos ha garantizado la libertad de asociación; pero si no somos capaces de asociamos para gobemamos a nosotros mismos, ¿esto es culpa de quien nos preside desde el gobiemo? Tenemos poderosos instrumentos para conseguir nuestra regeneración ${ }^{14}$.

Es el mismo tono, la misma impaciencia, la misma radicalidad que muchos otros tantos pensadores clásicos: "no existe, pues, nada mas sagrado que el derecho del prójimo (...) Aquel que no lleva a cabo acción benevolente alguna, pero tampoco ha lesionado nunca el derecho de los demás, siempre puede ser tenido por justo y, de ser todos así, no existiría la pobreza. En cambio, quien ha practicado buenas obras durante toda su vida, pero ha zaherido el derecho de un solo hombre, no podrá borrar esta iniquidad con todas sus caridades"2ul.

Este abuso de citas no es con el fin de agobiar al lector sino para generar una contraposición evidente con el lenguaje actual. Tómese al azar cualquier libro de derecho público, cualquier tratado de derecho civil o procesal y se verá como proliferan las citas de leyes, las explicaciones obvias, las repeticiones, los consejos "prácticos" o, algunas veces, la erudición y la lucidez en el análisis, pero siempre se respetará el estilo sin fuerza ni convicción que han impuesto la manualística y el derecho de los especialistas. Pero no se trata de un simple problema de palabras o estilos. Hoy pensamos al derecho como un indicador moral, como un consejo a los gobemantes y a los ciudadanos, como las reglas que rigen el trabajo de los abogados, como la expresión de las doctrinas de los teóricos, pero no como un instrumento político al servicio de los más débiles. Esta concepción se ha trasladado incluso a los derechos fundamentales y en muchos de sus doctrinarios se encuentra la misma falta de fuerza, de sentimiento y de convicción. La misma tibieza frente al incumplimiento masivo y sistemático de esos derechos. La co- 
munidad jurídica ha perdido toda capacidad de escándalo y las violaciones más flagrantes y cotidianas son asimiladas como si fueran ya elementos del medio ambiente.

La idea central de este ensayo es la siguiente: si pretendemos que la democracia se convierta en un instrumento efectivo para la construcción de una sociedad más justa, ella debe ser utilizada en todos sus instrumentos y todas sus dimensiones, no de un modo parcial o medroso, sino con profundidad y audacia. Así y solo así, la democracia será una concepción política que entusiasme y cause adhesión en una sociedad profundamente desigual y fragmentada, que desmiente día a día los sustentos primarios del mismo ideal democrático ${ }^{21}$. Dentro de los instrumentos de profundización de la democracia se encuentra la lucha por la legalidad, que también debe abandonar su tono apático, falsamente profesional y acomodaticio para convertirse en un discurso combativo y radical. Ello se puede hacer recuperando tradiciones, que precisamente veían en esta lucha radical por la legalidad uno de los instrumentos centrales de la emancipación del despotismo, la superstición y la servidumbre. No podemos pretender que los distintos sectores sociales se entusiasmen y utilicen la legalidad si ella es sinónimo de trampa, laberinto, falsedad, engaño, sutileza fútil, tibieza, rebuscamiento, farsa y privilegio encubierto. Menos aún podemos pretenderlo cuando esos mismos sectores, además, contraponen fácilmente lo que dice la ley con una realidad cotidiana de ilegalidad manifiesta que no logran revertir y ni siquiera es percibida como una situación escandalosa.

Pero queda subsistente un problema: ¿Cómo es posible la lucha por el cumplimiento de la ley si los tribunales no están dispuestos a aplicarla de un modo estricto?

\section{Los sistemas judiciales como nuevos espacios de lucha política}

Más allá de discusiones teóricas, nadie niega que la eficacia del derecho dependerá en buena medida de la eficacia de los tribunales. A su vez, la misma fortaleza de los tribunales dependerá de la fuerza que la ley tenga en una determinada sociedad. Ambas dimensiones son construcciones políticas que también se implican mutuamente. Fuerza de la ley, fuerza de los tribunales. Por eso, si se quiere construir una democracia que tome en serio la ley y se quiere luchar por la ley, para que ella sirva de instrumento para compensar y allanar las desigualdades sociales, entonces se deberá también tener una política de igual característica frente a los sistemas judiciales.

Ello tiene dos dimensiones, una la crítica radical al sistema inquisitivo, herencia colonial que aún pervive y constituye una pesada carga autoritaria sobre nuestros pueblos. En segundo lugar, una práctica política nueva de fortalecimiento de los sistemas judiciales. 
La crítica radical al sistema inquisitivo y sus consecuencias culturales nos sirve para hallar los componentes estructurales que impiden una verdadera independencia judicial, que muestran las razones de tribunales atrapados en sus propias rutinas y trámites e incapaces de dotar de eficacia a las leyes más elementales, entre ellas las Constituciones, que siguen sin ser cumplidas en nuestra administración de justicia. Está crítica radical nos muestra también el modo como estos sistemas judiciales, construidos verticalmente, sirven al poder concentrado y son factores de debilitamiento de la fuerza de la ley.

Para poder realizar una nueva práctica de construcción de poder para el Poder Judicial es necesario, en primer lugar, tomar conciencia que los sistemas judiciales son espacios políticos donde se juegan relaciones de poder, vinculadas a una específica función de gobierno (juzgar y custodiar la eficacia de la ley) que hasta ahora ha estado sustraída del proceso de democratización. Un espacio político que necesita ser transparentado como tal y al que deben ingresar nuevos sujetos, que no respondan a los intereses corporativos de la comunidad jurídica.

América Latina debe construir una nueva teoría política sobre lo judicial. No ha sido una preocupación teórica prioritaria desde las ciencias políticas y desde el derecho constitucional no se ha profundizado lo suficiente. Construir una teoría política de la justicia en democracias pobres no es sencillo, mucho menos sencillo si se busca integrar el aparato conceptual de varias disciplinas y se intenta eludir las trampas teóricas de la ratificación o la personificación del poder. Urge, pues, reflexionar sobre lo judicial como un espacio en el que concurren, disputan o se equilibran distintas fuerzas sociales; espacio en donde se organizan e interactúan diversas instituciones, tanto públicas como privadas; en fin, un específico espacio social, más proclive a ser explicado como un campo de fuerzas que como una cosa, persona o función. Asimismo es necesario asignar verdaderas finalidades políticas a la administración de justicia, abandonando las formulaciones genéricas o los ideales puramente morales. Sus funciones de pacificación, seguridad, certidumbre, tolerancia, etc., deben ser desarrolladas con mayor extensión y mayor precisión, para que la justicia tenga finalidades políticas concretas, dentro del proceso político particular de cada sociedad. Deberíamos, también, tener mayor capacidad para explicar los procesos políticos internos dentro del espacio judicial, así como la integración de lo judicial en el marco general de los problemas de gobierno y su eficacia. Otro de los temas centrales de una teoría política sobre la administración de justicia es la construcción de un lenguaje político para el Poder Judicial, no sobre él. Los jueces de Latinoamérica carecen de un adecuado lenguaje político. Finalmente, también es un punto central de una teoría política del Poder Judicial lo concerniente a los modos de acumulación de poder, propios del Poder Judicial. ¿Cómo se construye un Poder Judicial independiente, es decir, según un proceso propio y autónomo de acumulación de poder? Ello permitiría cons- 
truir nuevas estrategias de poder para el Poder Judicial que rompan la lógica peticionaria, propia del sistema inquisitivo ${ }^{22}$.

Pero a ese espacio que debe ser transparentado y democratizado, para que se modifiquen prácticas seculares que le impiden realizar su específica función de gobierno, deben ingresar nuevos actores sociales. Aunque el lenguaje parezca inapropiado no deja de ser exacto: los sistemas judiciales son nuevos espacios de lucha política en América Latina. No porque debemos esperar todo de ellos, tampoco porque todo se solucionará a través de las leyes, mucho menos porque puedan reemplazar a los lugares centrales del debate político (los parlamentos, los partidos políticos, los espacios públicos, etc.), sino porque la ley es un instrumento necesario para la profundización de la democracia y ésta, a su vez, es una condición indispensable para su legitimidad y permanencia en el tiempo. Radicalizar la lucha por la legalidad obliga a democratizar los sistemas judiciales para empujarlos a que cumplan su función de gobierno.

Si los tribunales no están dispuestos a hacer cumplir la ley, habrá que encontrar el modo de que lo hagan. No se trata de un problema moral. Lo podrá ser para cada juez individual, pero en términos generales es un problema político que afecta al conjunto de la vida social. Lograr que los tribunales garanticen el cumplimiento de la ley es una tarea política que debe movilizar a amplios sectores sociales y que reclama una acción concertada, no debe ser una simple exigencia. Para ello es necesario que esos mismos sectores sociales perciban ese objetivo como algo deseable y útil. Ello requiere todavía reflexión, debate y estrategia. Requiere, además, personas decididas a iniciar este proceso.

Hubo una época en la que algunas generaciones jóvenes encontraron que la lucha por la legalidad era un proyecto político que entusiasmaba. No sólo por los ideales de igualdad y libertad que esa lucha encamaba, sino por la eficacia que le asignaban a esa tarea. Muchos de nuestros mejores patriotas han pertenecido a esas generaciones y muchos de los mejores esfuerzos estuvieron orientados a construir la vigencia de la ley en nuestros países. El estado actual de impunidad, anomia y descreimiento hacia la ley parecen ser los signos más evidentes de su fracaso. Quizás sea así. Pero también la sociedad de privilegios recibió heridas profundas y hoy necesita renovar cotidianamente sus disfraces para sobrevivir y perpetuarse.

Quizás también comience nuevamente una época en la que ser demócrata en América Latina ya no sea tan cómodo ni tan aceptado socialmente. Quizás recordarle a la democracia sus promesas elementales comience a ser molesto e irritante. Seguro aparecerán de inmediato los prudentes, que reclamarán moderación; o los eficientes, que reclamarán orden. Ya merodean los iluminados, que reclamarán todo el poder o los violentos que no creen en la democracia misma. Historias conocidas y repetidas. Pero seguro que ahora, como antes, también aparecerán quienes saben que la democracia no es sólo fiesta de recuperación, 
sino una tenaz y paciente construcción colectiva y cuando las leyes - la austera, equitativa y clara ley republicana, no el desborde inflacionario de leyes incumplidas - "se cumplan religiosamente y se tengan por inexorables como el Destino", la República, la democracia y el Estado de derecho, hoy inseparables compañeros de ruta, volverán a ser un proyecto político que entusiasme como antaño.

A las generaciones más jóvenes les corresponde evitar que las derrotas se repitan y la desesperanza crezca. Ese es el desafío y esa es la tarea. Radicalizar la lucha por la legalidad es el nombre de una batalla de nuestra época, que todavía busca una generación entusiasta y comprometida.

\section{Notas}

1. Director del Instituto de Estudios Comparados en Ciencias Penales y Sociales (INECIP), Buenos Aires, Argentina. Actualmente cursa la carrera de doctorado en filosofía en la UCA de San Salvador.

2. Manuel Scorza, Garabombo el invisible, Monte Avila Editores, Caracas, 1977, p. 207.

3. Carlos Santiago Nino: Un país al margen de la ley, Emece, Buenos Aires, 1992, p. 25.

4. Francisco Tomás y Valiente, De la administración de Justicia al Poder Judicial, Ed. Ministerio de Justicia, Madrid, 1990.

5. Cayetano Filangieri, Ciencia de la Legislación, Traducción de don Jaime Rubio, 3a. edición, Tomo I, Madrid, 1822, p. 13.

6. J. Rousseau, El contrato social, libro IV, Cap. I.

7. B. de Montesquieu, Del Espíritu de las leyes, Libro XIX, Cap. XVI.

8. Bernard Scwartz, Algunos artífices del derecho norteamericano, traducción de Rubén Laporte, Ed. Abeledo Perrot, Buenos Aires, 1989, p. 25.

9. Enrique De Gandía, Simón Bolivar, su pensamiento político, Biblioteca de la Academia Nacional de Historia, 46, Caracas, 1984, p. 23.

10. Op. cit., p. 23.

11. "Proyecto de Constitución para Bolivia", 25 de mayo de 1826, Obras Completas, Edición Lex, La Habana, 1947, Vol. II, p. 1226.

12. Op. cit, p. 1225.

13. En la Antología titulada Pensamiento político de la emancipación, de la Biblioteca de Ayacucho, Venezuela, 1977, se recopilan extractos de proclamas, discursos y proyectos de ley que repiten las mismas ideas y el mismo entusiasmo por la legalidad por parte de los dirigentes de todos los movimientos libertadores de América Latina.

14. Rudolf V. Ihering, La lucha por el Derecho, traducción española de Diego de Santillan, Ed. Cajica, México, 1957. Existen otras traducciones al español.

15. Op. cit., p. 32.

16. Op. cit., p. 33.

17. Op. cit., p. 45.

18. Op. cit., p. 140-141.

19. Franceso Carrara, “Justicia y Libertad", en Opúsculos de Derecho Penal, Ed. Temis, 
Bogotá, Vol. III.

20. Immanuel Kant, Lecciones de Ética, traducción de Rodríguez Aramayo y Roldán Pandero, Editorial Crítica, Grijalbo, Barcelona, 1988, p. 256.

21. Para un planteamiento más extenso ver Alberto M. Binder, "La sociedad fragmentada", Revista Nueva Sociedad, Caracas, 111, p. 100.

22. Ver Alberto M. Binder, "Reforma de la justicia: del programa político al programa teórico". En Congreso de Derecho Procesal, Santiago de Chile, 1997, Universidad Diego Portales. Se ha extraído el párrafo como síntesis de lo que se desarrolla en esa ponencia con mayor extensión. Ver, asimismo, "Red Latinoamericana para la democratización de la justicia, Agenda y materiales de Trabajo de los Foros regionales", PNUD Y Fundación Konrad Adenauer, Ciedla, 1998. 